\title{
"Eu tenho saudades daquela época": lembranças do esporte escolar extracurricular curitibano (1980-1990)
}

\author{
"I have missing of that time": memories about after school sports of Curitiba (1980-1990) \\ "Echo de menos ese tiempo": recuerdos del deporte escolar extracurricular en Curitiba \\ (1980-1990)
}

Pauline Peixoto Iglesias Vargas ${ }^{\mathrm{a}, *}$ (D), Jonathan Rocha de Oliveira ${ }^{\mathrm{a}}(\mathbb{D})$, André Mendes Capraro $^{\mathrm{a}}$ (D)

Palavras-chave

Esporte;

Escola;

História;

Memória.

\begin{abstract}
RESUMO
O presente estudo visou retratar a prática do esporte escolar extracurricular em escolas particulares de Curitiba-PR, entre os anos de 1980 e 1990. O método de investigação utilizado foi a História Oral. Para tanto, foram ouvidos atletas, técnicos e gestores que o vivenciaram. Dentre os achados da pesquisa destacam-se: a Copa Intercolegial Itaú marca a memória dos entrevistados como símbolo do esporte escolar curitibano da época, assim como o Ginásio do Tarumã como local de memória; o esporte é tido como puro e benevolente pelos entrevistados, destacando a sua importância na formação humana; alguns nomes de protagonistas do esporte nacional passaram pelas quadras escolares curitibanas.
\end{abstract}

Keywords

Sports;

School;

History;

Memory.

\begin{abstract}
The present study portrayed the practice of performance school sports in private schools in Curitiba-PR, between 1980 and 1990. The research method used was Oral History. For doing so, Managers, coaches, and athletes who actively participated in the process were interviewed. Among the research findings, the following stand out: the Copa Intercolegial Itaú marks the memory of the interviewees as a symbol of the school sports of Curitiba at the time, as well as the Ginásio do Tarumã as a place of memory; sport is seen as pure and benevolent by the interviewees, highlighting its importance in human formation; some names of protagonists of the national sport passed through the school courts in Curitiba.
\end{abstract}

\section{RESUMEN}

Este estudio tuvo como objetivo retratar la práctica de deportes escolares extracurricular en escuelas privadas en Curitiba-PR, entre 1980 y 1990. El método de investigación utilizado fue Historia Oral. Con este fin, se escucharon gerentes, atletas y entrenadores que lo escucharon. Entre los hallazgos de la investigación se destacan: la Copa Intercolegial Itaú marca la memoria de los entrevistados como símbolo del deporte escolar de Curitiba en ese momento, así como el Ginásio do Tarumã como lugar de memoria; el deporte es visto como puro y benevolente por los entrevistados, destacando su importancia en la formación humana; algunos nombres de protagonistas del deporte nacional pasaron por las canchas escolares de Curitiba. 


\section{INTRODUÇÃO}

A presença do esporte no ambiente escolar é inegável, porém, a relação entre estes dois elementos não foi, nem é linear, muito menos tranquila. Bracht (2009, p. 173) explica que "[...] essa questão de se, e como, o esporte pode/deve ser assumido pela instituição educacional acompanha a história da Educação Física e sempre foi polêmica". Neste sentido, diversos estudos (Coletivo de Autores, 1992; Betti, 1997; Daolio, 1998; Bracht, 2000), sobretudo os publicados logo após o período da ditatura civil-militar nacional, tencionaram a finalidade e o formato do uso dos esportes dentro das instituições de ensino, em especial, como conteúdo da Educação Física curricular (Silva et al., 2020).

No entanto, o esporte esteve e está presente nas escolas também de maneira extracurricular e o seu formato e objetivo passaram por transformações ao longo dos anos. Para Bassani et al. (2003), o esporte praticado fora da grade curricular tem destacada presença nas instituições de ensino. De acordo com Luguetti et al. (2015), as atividades esportivas extracurriculares podem desempenhar um papel de prática pedagógica complementar às aulas de Educação Física.

Pois bem, nas décadas de 1980 e 1990 em Curitiba o esporte escolar extracurricular era oferecido pela maioria das instituições de ensino particular, de forma gratuita (quando não em um programa de bolsas de estudo). Os colégios da época organizavam times de modalidades diferentes para representá-los em competições escolares, estaduais e, algumas vezes, nacionais. Neste contexto, quais foram as experiências proporcionadas pelo esporte extracurricular curitibano aos atletas e professores na referida época?

Este artigo é parte de uma pesquisa maior que pretendeu retratar a prática de esporte extracurricular em escolas particulares de Curitiba, entre os anos de 1980 e 1990, a partir das memórias de gestores, técnicos e atletas esportivos que o vivenciaram. Neste recorte, foram valorizados os discursos, ressaltando as lembranças individuais e coletivas acerca do fenômeno. Para tanto, "as boas lembranças" do esporte extracurricular e as principais lembranças dos entrevistados foram apresentadas.

\section{ASPECTOS METODOLÓGICOS}

Para atingir os objetivos expostos, utilizou-se o aporte teórico-metodológico da História Oral. Alberti (2013, p. 155) esclarece o método:

A História Oral consiste na realização de entrevistas gravadas com indivíduos que participaram de, ou testemunharam, acontecimentos e conjunturas do passado e do presente. Tais entrevistas são produzidas no contexto de projetos de pesquisa, que determinam quantas e quais pessoas entrevistar, o que e como perguntar, bem como que destino será dado ao material produzido.
No intuito de encontrar pistas iniciais para a construção da narrativa proposta, foi realizada a escolha do primeiro entrevistado, guiada pelo objetivo da pesquisa, a partir da posição do colaborador dentro do grupo e do significado de sua experiência perante o tema. Em síntese, este entrevistado é denominado de "ponto zero". A primeira entrevista é muito valorizada nas pesquisas em História Oral, pois a partir dela emergem elementos que devem ser contemplados nas próximas (Meihy e Holanda, 2014).

Foi escolhido, então, o professor Mauro Marturelli Júnior para ser o "ponto zero" desta pesquisa. Em razão de que o referido professor atuou como técnico de futsal, de uma das escolas particulares de Curitiba, no período do recorte temporal deste trabalho. Após o contato inicial, o professor se propôs a colaborar com a pesquisa, consequentemente, gerando a primeira fonte oral. Para coletar as demais "vozes" foram escolhidos gestores, técnicos e atletas esportivos de diferentes modalidades, os quais atuaram em escolas citadas, a partir da primeira entrevista. Sendo eles, o professor Marcos Mathias Lamers que atuou por cerca de 15 anos no esporte extracurricular, dentre as décadas de 1980 e 2000. A professora Nádia Dalla Barba que vivenciou o esporte extracurricular no final da década de 1980 como atleta do handebol e, posteriormente, atuou com técnica da mesma modalidade em instituição de ensino. Roberley Leonaldo, mais conhecido no âmbito do esporte por "Rubinho", iniciou a prática do voleibol em escolas curitibanas e, posteriormente, migrou para clube. O professor Newton Zanon que foi atleta, técnico e, posteriormente, gestor de esporte de uma instituição de ensino de Curitiba até os finais dos anos 1990. E, por fim, o professor Nelson Rodrigues que, assim como os demais entrevistados, teve o seu primeiro contato com o esporte na escola. Ele passou de atleta a técnico esportivo e se envolveu com políticas públicas para o esporte no estado do Paraná. Sendo assim, foram ouvidos ${ }^{1}$ seis protagonistas do "esporte extracurricular curitibano", sendo eles profissionais atuantes nas décadas de 1980 e 1990.

A Tabela 1, a seguir, apresenta as informações detalhadas a respeito dos entrevistados. Os itens esporte, função e colégio referem-se ao envolvimento dos entrevistados com o fenômeno, durante as décadas de 1980 e 1990.

As entrevistas foram realizadas presencialmente, em locais e horários indicados pelos próprios colaboradores, que foram previamente contatados e informados acerca dos objetivos e procedimentos da proposta. 0 roteiro foi organizado com perguntas por eixos, os

\footnotetext{
1 A presente pesquisa faz parte de um projeto maior, aprovado pelo Comitê de Ética em Pesquisa do Instituto de Ciências Humanas da Universidade de Brasília - CEP/IH, mediante o parecer consubstanciado número 1.469.110. Número de registro no CONEP: 51225615.5.0000.5540.
} 
Tabela 1. Apresentação dos entrevistados.

\begin{tabular}{|c|c|c|c|c|c|}
\hline Entrevistado & Esporte & Função & Colégio & $\begin{array}{c}\text { Função no momen- } \\
\text { to da entrevista }\end{array}$ & Local da entrevista \\
\hline Mauro Marturelli Jr. & $\begin{array}{l}\text { Futsal/Futebol de } \\
\text { campo }\end{array}$ & Técnico & Positivo & $\begin{array}{l}\text { Professor da } \\
\text { disciplina de } \\
\text { Futebol em IES }\end{array}$ & $\begin{array}{l}\text { Universidade } \\
\text { Positivo }\end{array}$ \\
\hline $\begin{array}{l}\text { Marcos Mathias } \\
\text { Lamers }\end{array}$ & $\begin{array}{l}\text { Futsal/Futebol de } \\
\text { campo }\end{array}$ & Atleta e técnico & $\begin{array}{l}\text { Marista Santa } \\
\text { Maria }\end{array}$ & $\begin{array}{l}\text { Coordenador de } \\
\text { futebol de campo } \\
\text { do Paraná Clube }\end{array}$ & $\begin{array}{l}\text { Centro de } \\
\text { Treinamento do } \\
\text { Paraná Clube }\end{array}$ \\
\hline Nádia Dalla Barba & Handebol feminino & Atleta e técnico & Barddal & $\begin{array}{l}\text { Coordenadora } \\
\text { de academia de } \\
\text { ginástica }\end{array}$ & $\begin{array}{l}\text { Universidade } \\
\text { Positivo }\end{array}$ \\
\hline $\begin{array}{l}\text { Roberley Leonaldo } \\
\text { "Rubinho" }\end{array}$ & Voleibol & Atleta & Barddal & $\begin{array}{l}\text { Assistente técnico } \\
\text { da seleção } \\
\text { brasileira masculina } \\
\text { de voleibol }\end{array}$ & $\begin{array}{l}\text { Universidade } \\
\text { Federal do Paraná }\end{array}$ \\
\hline Newton Zanon & $\begin{array}{l}\text { Futsal/Futebol de } \\
\text { campo }\end{array}$ & Técnico e gestor & Positivo & $\begin{array}{l}\text { Diretor de esportes } \\
\text { da Secretaria } \\
\text { Municipal de } \\
\text { Esportes, Lazer e } \\
\text { Juventude }\end{array}$ & $\begin{array}{l}\text { Secretaria } \\
\text { Municipal de } \\
\text { Esportes, Lazer e } \\
\text { Juventude }\end{array}$ \\
\hline Nelson Rodrigues & $\begin{array}{l}\text { Handebol } \\
\text { masculino }\end{array}$ & Técnico e gestor & Positivo e Expoente & $\begin{array}{l}\text { Administrador da } \\
\text { carreira esportiva } \\
\text { do atleta olímpico } \\
\text { Henrique Rodrigues } \\
\text { (seu filho) }\end{array}$ & $\begin{array}{l}\text { Residência do } \\
\text { entrevistado }\end{array}$ \\
\hline
\end{tabular}

Fonte: os autores (2020).

quais abordavam os seguintes temas: história de vida esportiva do entrevistado, a organização/estrutura do esporte dentro da escola na época, incentivos e valores do esporte escolar, escolas e técnicos da época e demais reminiscências. Os entrevistados assinaram o Termo de Consentimento Livre e Esclarecido (TCLE) e concordaram com a utilização dos seus nomes reais para fins de publicação acadêmica.

Todas as entrevistas foram transcritas na íntegra e, posteriormente, passaram por pequenas edições. 0 resultado da transcrição foi devolvido aos colaboradores a fim de que estes pudessem editá-los livremente (Alberti, 2013). Após este procedimento, as entrevistas tornaram-se fonte da pesquisa sendo analisadas com autonomia documental. A análise se deu a partir dos conceitos de memória e identidade, pois acredita-se que ao fazer a conexão com o passado, torna-o compreensível e significante para o presente (Pollak, 1992; Thompson, 1992; Lowenthal, 1998; Portelli 2010a, b). Sendo assim, observou-se a memória coletiva acerca de três temas, a saber: os valores atribuídos ao esporte, a Copa Intercolegial Itaú e alguns nomes e ícones esportivos que se formaram nas quadras escolares de Curitiba. Tais temas serão apresentados nos subtópicos seguir.

\section{VALORES ATRIBUÍDOS AO ESPORTE ESCOLAR EXTRACURRICULAR NA ÉPOCA (1980-1990)}

O tom nostálgico das entrevistas foi evidente, principalmente a partir do momento em que os entrevistados perceberam compartilhar da mesma identidade da entrevistadora. Em outras palavras, os entrevistados deixaram de forma paulatina as formalidades ao identificarem a participação da pesquisadora no esporte escolar. Pois bem, deste ponto em diante, surgiram os desabafos:

[...] começou a se trabalhar um monte de jogos cooperativos [...]. Eu acho que isso é uma coisa que o esporte trabalha muito: frustração! Hoje parece que não podemos frustrar... entendeu? (Lamers, 2016).

A tolerância à frustração citada pelo professor Mathias Lamers é um dos valores depositados ao esporte, em especial, quando se toma por balizador o esporte educacional. Surge, então, a benevolência empregada para esporte, "o mito do esporte" detentor de um poder gerador de pureza e bondade aos indivíduos (Coakley, 2007).

Nesta esteira, outros valores do esporte resplandecem nas narrativas:

[...] os atletas, quando eram destaque, ganhavam uma bolsa de estudos e tinha essa guerra de trazer um atleta da outra escola, de oferecer a bolsa, isso era muito saudável para o esporte. Não só para o esporte, como para os alunos. Porque era uma perspectiva de ascensão social, inclusive para as pessoas que não tinham muitas condições. Era uma oportunidade bem bacana que o esporte dava. E o esporte tem essa vantagem. Porque quando você está dentro da quadra, quando você está dentro do tablado, quando você está dentro da piscina, você não sabe a condição social de ninguém! São todos iguais na hora do gol, na hora do ponto, na hora da cesta, na hora da apresentação, você abraça todo mundo da mesma maneira! (Zanon, 2016). 
O esporte se apresenta, então, como significativamente capaz de igualar os diferentes extratos sociais de atletas dentro de uma mesma equipe. Todavia, o mesmo entrevistado comentou o cuidado que se tinha em não oferecer bolsas de estudos para "[...] crianças de uma realidade muito diferente". Segundo Zanon (2016), houve algumas tentativas sem sucesso, nas quais os atletas acabaram se frustrando por fazer parte de uma realidade social muito diferente dos demais atletas do colégio. Surge a contradição. A inclusão social que o esporte possibilitava, afirmada pelo entrevistado, é, de certo modo, contestada no seu próprio relato. Afinal, seria ingenuidade acreditar que o esporte, por si só, seria capaz de resolver problemas sociais (Silva e Starepravo, 2017).

Mesmo ciente de que não há um acordo na comunidade acadêmica no que tange aos valores ensinados com a prática esportiva, os relatos enfatizam tais argumentos:

[...] eu acho que o que ficou de mais legal de todos aqueles meninos que passaram pela nossa mão foi o legado de você formar não só o atleta, mas formar pessoas realmente com caráter, sabe? [...] nós sempre passávamos princípios de disciplina educacional: "olha, vocês têm que arrumar a cama, vocês têm que manter o quarto limpo, vocês têm que respeitar a fila, vocês têm que comer essa comida porque é o que todo mundo tá comendo" [...] então, a gente passou outros princípios. [...] o esporte tem muito disso, de você formar realmente o caráter, o cidadão [...]. (Marturelli, 2016).

[...] não tenho daquela época memórias negativas, eu acho que só positivas! Eu tive muitos alunos que acabaram seguindo no esporte, eu tive muitos alunos também que por interferência nossa, acabaram vindo a fazer uma Faculdade de Educação Física, pois se apaixonaram pelo que fazíamos [...]. (Lamers, 2016).

[...] formávamos o aluno além da parte técnica [...] os meninos que passaram conosco como atletas, eu não posso falar nada contrário a uma formação de vida saudável [...]. (Rodrigues, 2017).

Como artifício para reforçar os legados deixados pela prática esportiva de escolares nas décadas de 1980 e 1990, os entrevistados citaram conversas com outras pessoas envolvidas naquele processo. As falas direcionam para uma "memória coletiva" (Pollak, 1992) sobre os benefícios, para os alunos, da participação nas equipes esportivas:

[...] e eles [os ex-atletas] me falam: "- Pô, professor, precisava reunir aquele grupo, era tão bom! A gente aprendeu tanto, a gente cresceu tanto [...] eu aprendi muito nessa época, eu aprendi realmente as diferenças, eu nunca tinha arrumado uma cama na minha vida" [...]. (Marturelli, 2016).
Não obstante, de forma paradoxal, os entrevistados reforçaram os legados do esporte relativizando as condições técnicas, deixando sinais para que se questione a finalidade do esporte escolar extracurricular, como revela Rodrigues (2017): "[...] não precisam e nem precisavam ser atletas com as melhores condições técnicas na modalidade, mas eram atuantes, tinham um convívio, certamente deixou um legado para o futuro".

Há indícios para a compreensão de que o esporte, como foi tratado naquele momento, não seja o modelo da atualidade. Sobre isso, Marchi (2005), ao tratar do processo de espetacularização do voleibol, destaca que o esporte, até a década de 1980 era uma prática exclusiva de escolas e clubes. Depois disso, passou a ser uma prática regida pela lógica mercadológica.

Não é possível entender esses fatos sem conectálos ao momento político do país. Afinal, o país estava vivendo o processo de redemocratização pós ditadura militar. O esporte, sobretudo no contexto escolar, passou a ser visto como demasiadamente tecnicista, por conta da forma como este foi desenvolvido durante a ditadura militar (Feron e Silva, 2007). As críticas ao ensino do esporte em escolas reverberam e causaram a sua paulatina desvalorização (Bracht, 2000; Bassani et al., 2003; Navarro et al., 2020; Vargas e Capraro, 2020). A respeito disso, Mathias Lamers (2016) sugere: “[...] você tem que ter o equilíbrio, porque antigamente era tudo voltado para a parte esportiva, hoje talvez esteja tudo muito voltado somente para a parte social!".

Partindo das concepções de memória e identidade amparadas na proposta de Michael Pollak (1992), foi possível verificar uma flutuação de memória. Talvez grande parte dos fatos destacados ao longo das entrevistas, durante as décadas de 1980 e 1990, não foi tão relevante para os entrevistados, mas, vinte anos depois, esses fatos passaram a ser significativos em função do momento em que estavam sendo verbalizados. Muitas vezes, durante as narrativas, os colaboradores fizeram comparativos com os dias atuais, mencionando como naquela época o esporte era mais valorizado e importante para as instituições de ensino.

Será que todas as famílias concordaram com os métodos de treinamento? Será que naquele momento somente ocorreram episódios positivos? O fato dos entrevistados terem focado suas narrativas nos bons momentos, auxilia no sentido de indicar para uma seleção memorialista, já que, conforme explica Pollak (1992, p. 203), "Nem tudo fica gravado. Nem tudo fica registrado". Afinal, ao lembrar do passado, sobretudo, o já finalizado, há a tendência de ser uma memória polarizada, em síntese, "tudo bem, quando termina bem".

O fato da memória ser seletiva (da mesma forma que qualquer outro documento) e, consequentemente, ser um fenômeno construído, se destacou mais uma vez, visto que os fatos recordados pelos entrevistados eram sempre positivos e enaltecedores, a exemplo: "[...] Então, eu só tenho daquela época... boas lembranças 
[...]" (Marturelli, 2016) e "[...] eu tenho saudades daquela época [...]"2 (Lamers, 2016).

\section{A CONSTRUÇÃO MEMORIALÍSTICA DE UM SÍMBOLO COLETIVO: A COPA INTER- COLEGIAL ITAÚ}

Ao ouvir os entrevistados, apresentou-se um símbolo do esporte extracurricular curitibano dos anos finais da década de 1980, a Copa Intercolegial Itaú. Segundo Rodrigues (2017), essa foi a primeira parceria público-privada para realização de um evento esportivo no estado do Paraná. O projeto, baseado em um modelo que já estava ocorrendo na cidade de São Paulo, foi criado como estratégia do referido banco para divulgar a sua marca na cidade de Curitiba. Por outro lado, a Secretaria de Estado do Paraná pretendia iniciar o projeto de forma embrionária na capital paranaense e, subsequentemente, ampliá-lo para a realização em parceria dos Jogos Abertos do Paraná, Jogos da Juventude e Jogos Escolares do Paraná. Zanon (2016) explicou a parceria com entusiasmo:

[...] o Banco Itaú passou a patrocinar os jogos intercolegiais da prefeitura, então, mudou de patamar. Porque no serviço público sempre há restrições financeiras para realizar eventos. Quando apareceu a verba do Banco Itaú foi uma coisa enorme, para a época. Eles investiam nas aberturas, nos desfiles, em personalidades que traziam, a premiação era muito bonita, as medalhas eram enormes, os técnicos ganhavam um quadro com as classificações e tudo mais $[\ldots]$.

Mas por que a Copa Itaú se transformou numa memória tão importante dos participantes? Nádia Dalla Barba (2016) respondeu com certa confusão: "[...] talvez, por terem mais modalidades envolvidas? Se bem que os Jogos Escolares também tinham mais modalidades, mas não tinha o mesmo brilho, não sei o que tinha aquela Copa Itaú, era muito legal [...]". A mesma euforia ao falar do evento foi constatada em outra entrevista:

[...] era fantástico! Porque você se preparava, as escolas tinham uma rivalidade grande [...] como tinha recurso, a arbitragem era bem paga, você contratava os melhores árbitros, tinha a premiação que era bonita, o marketing que saía na televisão era grande [...]. (Rodrigues, 2017).

O evento que ocorreu essencialmente com modalidades coletivas foi rememorado por dirigentes esportivos, atletas e técnicos de maneira singular. A relevância da competição, a qualidade da premiação, e a rivalidade entre instituições de ensino explicam o saudosismo dos entrevistados. O professor Nelson Rodrigues (2017) enfatizou a sua participação na criação

2 Esta frase na narrativa transformou-se em título do artigo. do evento "[...] A Copa Itaú foi o marco nosso!". Depois explicou:

[...] Primeiro que ela dava premiação bonita, não era medalhinha de lata, eram as medalhas que pareciam medalhas de Olimpiada, enorme! Troféu! Criou-se a rivalidade de vencer a Copa Itaú. Então, tinha prêmio até para torcida, tinha prêmio para o melhor desfile na abertura [...]. (Rodrigues, 2017).

O evento vai além de uma memória nostálgica. Os entrevistados, ao recordarem a Copa Itaú, silenciaram-se como se estivessem voltando no tempo, como se quisessem por uns minutos reviver aquela competição, pareciam visualizar a premiação e a cerimônia de abertura.

[...] Era no Ginásio do Tarumã, aquilo é uma lenda [...] só de ir ao desfile [de abertura dos Jogos] no Tarumã, eu não sei, mas era... nossa! Tinha um holograma que era jogado, lembra? [...] Era o máximo aquilo, mas é uma opinião que não é só minha [...]. Ficávamos esperando o ano inteiro para poder jogar aquela copa [...]. (Dalla Barba, 2016).

Os colaboradores, ao rememorarem a Copa Intercolegial Itaú, destacaram o Ginásio do Tarumã. O local parece alcançar o status de patrimônio de memória social, que está além das competições lá sediadas. O lugar produz nos entrevistados recordações que entrelaçam a vida pessoal e o local, sendo este tomado como guardião de uma prática esportiva, ou seja, um lugar de memória. Local onde os participantes significam o seu passado, e ao qual atribuem valor afetivo (Andrade, 2008).

[...] O Tarumã, nossa! Era uma loucura! Então, o envolvimento das escolas, era uma coisa fantástica, mas por quê? Porque tinha um respaldo atrás, tinha um marketing forte interno das próprias escolas em cima do esporte. O esporte era o carro-chefe das escolas [...]. (Rodrigues, 2017).

Percebe-se aqui a importância que era dada ao esporte no sentido de marketing institucional. Não somente era utilizado pelos colégios, mas também o esporte promovia a marca, no caso a instituição financeira. Esse processo de espetacularização e mercantilização do esporte também foi evidenciado por Cruz et al. (2020), na década de 1990, com a instalação do Projeto Rexona, em Curitiba. O Projeto tinha o objetivo de projetar o Paraná no cenário esportivo nacional, a partir da parceria entre o poder público e a iniciativa privada. O Projeto Rexona também utilizava as instalações do Ginásio Tarumã, local que sediava grandes eventos esportivos na cidade, especialmente até o final dos idos de 1990. O local foi palco dos desfiles de abertura das edições da Copa Intercolegial Itaú:

[...] era uma coisa enorme! Eu lembro que a gente ia para abertura, porque tinha a premiação, tinha a pontuação geral. A gente sempre brigava pela 
pontuação geral e na pontuação geral contava o desfile de abertura, contava a melhor torcida, então, eles faziam assim as aberturas eram enormes, a gente chegou a levar carro alegórico para dentro do Tarumã. [...]. (Zanon, 2016).

Contudo, a Copa Intercolegial Itaú, depois de algumas edições de realização, deixou marcas nas memórias dos entrevistados. Neste sentindo, um dos entrevistados usou o presente para questionar as mudanças ocorridas:

[...] O que está acontecendo? Alguma coisa está errada! [...] você levava a escola inteira para torcer, para ter o maior número de torcida, porque tinha prêmio! Você ganhava as coisas, você era valorizado! Então, é o que o norte-americano faz e que nós não fazemos nunca, não é? [...]. (Rodrigues, 2017).

O apelo pela valorização esportiva fica evidente na fala do professor, que, ao comparar com a atualidade, remete ao contexto no qual, supostamente, estão inseridos os atletas norte-americanos. Sobre isso, Coakley (2007), ao justificar a necessidade de estudar os esportes nas diferentes sociedades, questiona os motivos da valorização do esporte em escolas norte americanas. Afinal, não é possível comparar o esporte em diferentes sociedades e períodos históricos, sem considerar que os esportes fazem parte de contextos sociais e culturais.

\section{TRAJETÓRIAS PROFISSIONAIS DOS PER- SONAGENS ENVOLVIDOS NO ESPORTE EXTRACURRICULAR NA ÉPOCA}

Outro ponto que merece destaque ao analisar as fontes da pesquisa refere-se aos caminhos profissionais $a$ posteriori, não somente dos entrevistados, mas de muitos dos envolvidos com o esporte curitibano da época. Dentre os entrevistados, o professor Mathias Lamers, que, depois de um período fora do Brasil, retornou e assumiu a coordenação de futebol do Paraná Clube. Já o professor Mauro Marturelli Júnior seguiu para o Ensino Superior, ligado a disciplinas com viés esportivo, tais como futebol e gestão esportiva.

O professor Nelson Rodrigues administrava a carreira esportiva do atleta olímpico Henrique Rodrigues, seu filho, no período da entrevista. Já o professor Newton Zanon, além de ser servidor da Secretaria de Esporte e Lazer para a Juventude (SMELJ) de Curitiba, no momento da entrevista estava na função de diretor de esporte da instituição. Dentre os entrevistados, Roberley Leonando seguiu carreira no voleibol profissional, se mantendo até os dias de hoje no cenário de alto rendimento.

No entanto, a professora Nádia Dalla Barba deixou o treinamento na época por questões pessoais, relacionadas ao nascimento de sua filha. Tal fato corrobora com o estudo de Ferreira et al. (2013), o qual apontou que a maioria das mulheres atuantes como treinadoras esportivas são solteiras e não possuem filhos, e aquelas que os possuem carregam, dentre tantas dificuldades, o desafio de conciliar a vida pessoal e afetiva com a carreira de treinadora.

Ainda no que tange à narrativa da única voz feminina desta pesquisa, pode-se inferir que há um predomínio da escolha narrativa de caráter pessoal. Ou seja, os marcos que a interlocutora usa para apoiar sua memória são, em geral, relativos à vida pessoal (o nascimento da filha, a mudança de escola e a transição da carreira de atleta para treinadora).

Com a exceção de Nádia Dalla Barba, os demais entrevistados seguiram carreira no esporte de rendimento, ou próximo disso. Outros técnicos do esporte escolar da época foram citados, enaltecendo-se inclusive o status por eles conquistados dentro da área esportiva, a saber: "[...] O caso do André Mattos que era do voleibol, hoje está no Comitê Olímpico Brasileiro" (Dalla Barba, 2016). De maneira símile, Edgar Hubner foi citado pelos entrevistados. Ele atuava na coordenação da Educação Física do Colégio Barddal (Leonaldo, 2016).

Ao citar os colegas que trabalhavam em diferentes esportes dentro das escolas curitibanas na época, Zanon (2016) completa: "[...] por aí você vê a qualidade dos professores que estavam lá (no esporte extracurricular)! Que todos se destacaram, mesmo depois que saíram de lá [...]". Alguns técnicos assumiram cargos na gestão educacional, mais uma vez manifestando a importância do esporte nas escolas, uma vez que os técnicos passavam por caminhos de crescimento profissional, a partir dos seus méritos esportivos.

A formação de atletas que, posteriormente, vieram a se destacar em âmbito nacional e internacional também foi tema da narrativa dos entrevistados, alguns exemplos mencionados: Lenamar Fiorese, que se tornou psicóloga da ginástica brasileira nos Jogos Olímpicos. Alice Maria Fernandez, ex-atleta da seleção brasileira de handebol, foi descoberta nas quadras do Colégio Barddal (Dalla Barba, 2016; Rodrigues, 2017).

$\mathrm{Na}$ esteira de registrar a memória daqueles que participaram do esporte extracurricular curitibano, surgiu também a lembrança de uma ginasta:

E quando a gente estava nessa fase áurea, no auge, nós tínhamos campeões brasileiros, nós tínhamos campeões pan-americanos, nós tínhamos uma menina na ginástica [...] investíamos muito nela, sonhávamos em ter uma atleta olímpica! Era a Cláudia Sperandio! [...]. (Zanon, 2016).

Ainda no que tange à tentativa de registrar outros atletas que se destacaram no esporte a partir do primeiro contato nas quadras escolares curitibanas, os relatos seguiram:

[....] nós tivemos alguns alunos que tiveram a experiência na Europa jogando em clubes italianos [...] tem alguns alunos que foram meus atletas que hoje 
são professores, inclusive treinadores do Paraná Clube 3 [...]. (Marturelli, 2016).

Obviamente, o próprio entrevistado Rubinho é um dos ícones do esporte atual que teve o seu primeiro contato com o esporte nas quadras escolares curitibanas, neste caso inicialmente em uma escola pública, o Colégio Leôncio Correia, para logo após receber uma bolsa do Colégio Barddal - aquele mesmo em que atuou Nádia Dalla Barba. Na atualidade (2020), ele é o técnico da equipe masculina adulta de voleibol do SESI de São Paulo. Seus relatos são perpassados pelo envolvimento no esporte e pelo seu protagonismo no campo esportivo atual.

Os professores que permaneceram atuando no esporte escolar também foram relembrados. Antônio Moresco atuou com esporte extracurricular no Colégio Padre João Bagozzi de Curitiba. O treinador de futebol de campo do Colégio Marista Paranaense na época, Alfredo Carlos Scremin também foi mencionado. Ele atuou no esporte extracurricular até o seu falecimento (2016). Vale ressalvar que os professores que permaneceram atuantes no campo esportivo escolar passaram por um processo de readequação de suas aulas/treinamentos. A exemplo disso, o professor Scremin, o qual permaneceu na escola como pessoa jurídica, terceirizando as atividades extracurriculares de futsal/futebol (Lamers, 2016).

Pois bem, cabe aqui uma ponderação. Obviamente, o esporte extracurricular curitibano, na década de 1980 e 1990, foi protagonizado por gestores, técnicos e atletas de escolas particulares que obtiveram destaque em seus papéis esportivos, como alguns exemplos de carreira supracitados. Ressalta-se que este cenário foi composto e vivenciado por, além dos entrevistados e dos casos ilustrativos nesse estudo, profissionais e alunos em outras instituições de ensino na cidade, os quais alguns destes não obtiveram a mesma notoriedade no esporte, na escola ou na mídia, consequentemente, recebendo pouca ou nenhuma atenção do meio acadêmico. Isto sinaliza outras perspectivas e facetas do esporte extracurricular de Curitiba na referida época, cuja a sua historiografia é formada por uma "multiplicidade de pontos de vista", como afirma Portelli (1997), que não devem ser desconsiderados na construção histórica do fenômeno.

\section{CONSIDERAÇÕES FINAIS}

A partir das narrativas dos entrevistados foi possível retratar uma versão do esporte extracurricular curitibano, abrindo o diálogo para a polissemia do esporte. Nesse sentido, vale destacar alguns resultados desta pesquisa: a Copa Intercolegial Itaú marca a memória dos entrevistados como símbolo do esporte escolar curitibano da época, assim como o Ginásio do

3 O atual (2020) preparador de goleiro do Coritiba Foot Ball Club, Thiago Mehl, foi aluno do professor Mauro Marturelli Júnior (Marturelli, 2016).
Tarumã como local de memória; o esporte é tido como puro e benevolente pelos entrevistados, destacando a sua importância na formação humana; alguns nomes protagonistas do esporte nacional passaram pelas quadras escolares curitibanas.

Acentua-se que a escolha das vozes foi realizada, de certa forma, arbitrária pelos pesquisadores, assim como a seleção de temas a serem abordados aqui, tudo isso sempre passando pelo crivo da cultura e experiência singular de quem gerou este produto final (Portelli, 2010a; Alberti, 2013). Neste sentido, ressalva-se que a escuta de pessoas que permanecem atuando no campo esportivo favorece relatos entusiasmados em relação ao fenômeno.

Tem-se a certeza de ter preenchido apenas algumas lacunas do esporte escolar extracurricular curitibano das décadas de 1980 e 1990. No mesmo sentindo, ao buscar nomes e representantes do fenômeno, tem-se a convicção de que outros personagens desta história ainda não foram ouvidos e lembrados. Porém, esse trabalho teve seu início e possibilita que novos pesquisadores investiguem outros atores do período em que o esporte escolar extracurricular foi retratado.

\section{FINANCIAMENTO}

Este estudo contou com o apoio financeiro da Coordenação de Aperfeiçoamento de Pessoal de Nível Superior (CAPES) e da Fundação Araucária.

\section{CONFLITOS DE INTERESSE}

Os autores declaram não haver conflitos de interesse.

\section{REFERÊNCIAS}

Alberti V. Manual de história oral. 3. ed. Rio de Janeiro: FGV; 2013.

Andrade C. Lugar de memória.... memórias de um lugar: patrimônio imaterial de Igatu, Andaraí, BA. Rev Tur y Patrim Cult. 2008;6(3):569-90. http://dx.doi.org/10.25145/j. pasos.2008.06.042.

Bassani JJ, Torri D, Vaz AF. Sobre a presença do esporte na escola: paradoxos e ambigüidades. Movimento. 2003;9(2):89-112. http://dx.doi.org/10.22456/1982-8918.2811.

Betti M. A janela de vidro: esporte, televisão e educação física. Campinas: Universidade Estadual de Campinas; 1997.

Bracht V. Esporte de rendimento na escola. In: Stigger MP, Lovisolo H, editores. Esporte de rendimento e esporte na escola. Campinas: Autores Associados; 2009.

Bracht V. Esporte na escola e esporte de rendimento. Movimento. 2000;6(12):1-11.

Coakley J. Sports in society: issues and controversies. 9th ed. New York: Mc Graw Hill; 2007. The sociology of sports.

Coletivo de Autores. Metodologia de ensino de educação física. São Paulo: Cortez; 1992.

Cruz KS, Salvini L, Marchi W Jr. O jogo de três toques: apontamentos histórico-sociais da estrutura do voleibol 
em Curitiba (1932-2015). Motrivivência. 2020;32(61):118. http://dx.doi.org/10.5007/2175-8042.2020e62787.

Dalla Barba N. Entrevista cedida aos pesquisadores. Curitiba; 2016.

Daolio J. Educação Física Brasileira: autores e atores da década de 1980. Campinas: Papirus; 1998.

Feron AV, Silva MM. A Igreja Do "Diabo" e a produção do conhecimento na Educação Física. Rev Bras Ciênc Esporte. 2007;29(1):107-22.

Ferreira HJ, Salles JGC, Mourão L, Moreno A. A baixa representatividade de mulheres como técnicas esportivas no Brasil. Movimento. 2013;19(3):103-24. http://dx.doi. org/10.22456/1982-8918.29087.

Lamers MM. Entrevista cedida aos pesquisadores. Curitiba; 2016.

Leonaldo R. Entrevista cedida aos pesquisadores. Curitiba; 2016.

Lowenthal D. Como conhecemos o passado. São Paulo; 1998. (Projeto História; 17).

Luguetti CN, Ferraz OL, Nunomura M, Böhme MTS. O planejamento das práticas esportivas escolares no ensino fundamental na cidade de Santos. Rev Bras Ciênc Esporte. 2015;37(4):314-22. http://dx.doi.org/10.1016/j. rbce.2015.08.011.

Marchi W Jr. O processo de ressignificação do voleibol a partir da inserção da televisão no campo esportivo. Rev Bras Ciênc Esporte. 2005;26(2):149-62.

Marturelli M Jr. Entrevista cedida aos pesquisadores. Curitiba; 2016.
Meihy JCSB, Holanda F. História oral: como fazer, como pensar. 2. ed. São Paulo: Contexto; 2014

Navarro RT, Mezzadri FM, Moraes e Silva M. The genesis of the sport for all campaign in Brazil as seen through the Jornal dos Sports in the 1970s. Sport Soc. 2020. No prelo. http:// dx.doi.org/10.1080/17430437.2020.1768241.

Pollak M. Memoria e identidade social. Estud Históricos. 1992;5(10):200-12.

Portelli A. Ensaios de história oral. São Paulo: Letra e Voz; 2010a.

Portelli A. História oral e poder. Mnemosine. 2010b;6(2):2-13.

Portelli A. O que faz a história oral diferente. São Paulo; 1997. p. 1-15. (Projeto História; 14).

Rodrigues N. Entrevista cedida aos pesquisadores. Curitiba; 2017.

Silva AFZ, Starepravo FA. Megaeventos Esportivos, Legados, Educação Física e Escola. Licere. 2017;20(1):1-37. http:// dx.doi.org/10.35699/1981-3171.2017.1585.

Silva BS, Souza ACF, Martins MZ. Desafiando o abismo tradicional: uma aproximação entre práticas inovadoras e o modelo de educação esportiva no âmbito da educação física escolar. Rev Bras Ciênc Esporte. 2020;42:e2023.

Thompson P. Vozes do passado. Rio de Janeiro: Paz e Terra; 1992.

Vargas PI, Capraro AM. "It was competitive, it was very competitive!": memory of school sports of performance in particular schools of Curitiba (1980-1990). J Phys Educ. 2020;31(1):1-9. http://dx.doi.org/10.4025/jphyseduc. v31i1.3111.

Zanon N. Entrevista cedida aos pesquisadores. Curitiba; 2016. 